\title{
Planning and optimising a digital intervention to reduce older adults' cognitive decline
}

Rosie Essery ( $\square$ r.a.essery@soton.ac.uk)

University of Southampton https://orcid.org/0000-0002-2702-6951

\section{Sebastien Pollet}

University of Southampton

Kirsten A. Smith

University of Southampton

Fiona Mowbray

University of Southampton

Joanna Slodkowska-Barabasz

University of Southampton

James Denison-Day

University of Southampton

Victoria Hayter

University of Southampton

Katherine Bradbury

University of Southampton

Elisabeth Grey

University of Bath

Max J. Western

University of Bath

Alexander Milton

University of Bristol

Anne E. Ferrey

University of Oxford

Andre Matthias Müller

National University Singapore Saw Swee Hock School of Public Health

\section{Beth Stuart}

University of Southampton

Nanette Mutrie

The University of Edinburgh

\section{Simon Griffin}

University of Cambridge

Tony Kendrick 
University of Southampton

\section{Bernard Gudgin}

Public and Patient Involvement Representative

\section{Rosemary Phillips}

Public and Patient Involvement Representative

\section{Tom Stokes}

Public and Patient Involvement Representative

John Niven

Public and Patient Involvement Representative

\section{Paul Little}

University of Southampton

\section{Lucy Yardley}

University of Southampton

\section{Research}

Keywords: cognitive-health, behaviour-change, physical activity, dementia, prevention, digital-intervention

Posted Date: April 2nd, 2020

DOI: https://doi.org/10.21203/rs.3.rs-20513/v1

License: (c) (i) This work is licensed under a Creative Commons Attribution 4.0 International License. Read Full License

Version of Record: A version of this preprint was published at Pilot and Feasibility Studies on August 18th, 2021. See the published version at https://doi.org/10.1186/s40814-021-00884-2. 


\section{Abstract}

Background By 2050 worldwide dementia prevalence is expected to triple, rising to 152 million. Affordable, scalable interventions are required to support protective behaviours such as physical activity, cognitive training and healthy eating. This paper outlines the development of 'Active Brains': a multidomain digital behaviour change intervention to reduce cognitive decline amongst older adults, and key findings arising from this process.

Methods A theory-, evidence- and person-based approach to intervention development was undertaken. Scoping reviews and behavioural analysis contributed to intervention planning. Optimisation involved qualitative interviews with 52 older adults with higher and lower cognitive performance scores. Data were analysed thematically and informed changes.

Results The development process synthesised findings from planning and optimisation activities. Scoping reviews and qualitative interviews suggested that the same intervention content should be suitable for individuals with higher and lower cognitive performance. Qualitative findings revealed that maintaining independence and enjoyment motivated engagement in intervention-targeted behaviours, whereas managing ill health was a potential barrier. Social support for engaging in such activities could provide motivation, but was not desirable for all. These findings informed development of highly acceptable intervention content and functionality for target users.

Conclusions A digitally-delivered intervention with minimal support appears acceptable and potentially engaging to older adults with higher and lower levels of cognitive performance. As well as informing our own intervention, the insights obtained through our development process may be useful for others working with, and developing interventions for, older adults and/or those with cognitive impairment.

\section{Background}

Fifty-million people worldwide currently have dementia (1). Cognitive impairment is even more common; Mild Cognitive Impairment ( $\mathrm{MCl}$ ) and Age-Associated Cognitive Decline (AACD) are estimated to affect nearly $20 \%$ of adults aged 60 and over $(2,3)$. Around $10 \%$ of $\mathrm{MCl}$ and AACD cases convert to dementia each year (4). The annual global cost of dementia is nearly US\$1 trillion with dementia prevalence expected to rise to 152 million by 2050 (5). Dementia and cognitive decline place unsustainable demand on health and social care systems worldwide, and pose substantial threat to individuals' independence and quality of life (6). Prevention and management of dementia are public health priorities (7).

Increasing evidence suggests that health-related behaviours (e.g., physical activity and a Mediterraneanstyle diet) and cognitive training are protective of cognitive health (7-11). Interventions targeting a single behaviour in individuals with and without existing cognitive impairment show some positive effects on cognitive outcomes (12-16). However, findings are mixed and often inconclusive, prompting investigation of multi-domain intervention strategies (7). Multi-domain interventions have also shown mixed results (17-19). Despite positive effects of a face-to-face (group and individual) delivered 
programme addressing diet, physical activity, cognitive training and managing vascular risk (17), such interventions tend to be resource-intensive, prompting calls for scalable, cost-effective approaches (7). Understanding which intervention components are useful and how to improve cost-effectiveness is a key challenge (Livingston et al., 2017).

Digital health-behaviour interventions have excellent potential to deliver content efficiently, effectively and accessibly at low cost (20). There is currently limited evidence about the potential of digitally-delivered multi-domain interventions to protect cognitive health. One pre-post design study showed promising effects of a digital intervention addressing behaviours including physical activity, diet, smoking, alcohol intake, and sleep, but did not measure cognitive outcomes (21). Furthermore, there is limited evidence about whether digital-delivery of interventions is feasible, engaging and acceptable in this context. Potential barriers to feasibility and acceptability relate to users' cognitive capacity and digital literacy. It is important to explore whether individuals with cognitive decline have different preferences and requirements for intervention functionality. Furthermore, whilst older adults' digital literacy is rapidly growing, there is still wide variation in ability and/or willingness to engage with digital health material (22, 23). It is therefore important to explore whether digital content and functionality can be made accessible and engaging for these users, and how best to achieve this.

This paper outlines the development of 'Active Brains': a low-cost, digitally-delivered, multi-domain intervention to reduce cognitive decline amongst older adults. Active Brains is for $60-85$ year-olds with and without existing cognitive impairment, and aims to reduce cognitive decline by addressing physical activity, cognitive training and healthy eating behaviours. Clear reporting of the development of new interventions avoids 'research waste' and duplication of ineffective, unfeasible or unacceptable interventions (24). In documenting this development process we aim not only to provide a clear account of how the intervention was created, but also to provide evidence about whether a digital intervention is a feasible, engaging and acceptable means of delivery in this context. The paper is broadly split into 'planning' and 'optimisation' sections that run through the 'Research Design and Methods' and 'Results' sections, reflecting the two phases of development. The 'Planning' section presents the theory-, evidenceand person-based 'Guiding Principles' and logic model that underpin intervention content and functionality. The 'Optimisation' section presents our qualitative findings about older adults' perceptions of cognitive health and associated protective health behaviours, as well as their feedback on all aspects of intervention content throughout development. We explain how these findings allowed Active Brains to be shaped by target users' expectations and preferences, whilst highlighting transferable insights and methods that could be applied across numerous behaviour change contexts.

\section{Methods}

Structure of the development process

Active Brains was developed according to a theory-, evidence- and person-based approach to intervention development (25-27). The knowledge generated from these approaches was triangulated to inform 
'guiding principles' (27) and a logic model outlining the programme theory underpinning the intervention. The development process was implemented in two phases: planning and optimisation. Although described separately, in practice these phases occurred as an iterative cycle (Fig. 1). Development focused on the physical activity and cognitive training intervention elements as the team had previously developed a healthy eating module that could be adapted for use in this context (28). Additional Table 1 summarises how each element of the Active Brains development process addresses recommended actions for intervention development (24). 
Table 1

The Active Brains Guiding Principles

Key findings from Literature

Older adults with cognitive impairment tend to experience difficulties in the domains of memory, language, thinking and judgement. Difficulties not so extensive that the individual requires assistance with activities of independent daily living $(49,53)$

Older adults with cognitive impairments that may affect Internet use are still actively engaging with technology (54) Good evidence of effectiveness and/or acceptability of various features/characteristics of interventions:

- Simple goal setting and action planning with clear explanation of benefits/ importance (55)

- Reinforcement/encouragement for achievements (50)

- Self-monitoring of physical activity behaviours, e.g. using a pedometer (47, 55)

- Social support in the form of activity suggestions to be done with others/ local group recommendations $(47,50)$; social element of cognitive training may also be beneficial (51)

- Promotion of autonomy (50)

Strength and balance exercises can be built into daily routines and activities (56)

Individuals more motivated to participate in, and have better recognition memory for, physical activity programmes paired with positively framed messages than in those with negatively framed ones (52) Loss of independence perceived as key threat of cognitive decline (45)

Older adults with cognitive impairments very interested in programs offering computer exercises to improve cognition as well as web-based interventions for a range of health concerns and lifestyle factors, including physical activity, diet and nutrition, social engagement (54) Enjoyment of activities is important (41, 42, 46)

Different/new activities such as strength, flexibility and balance exercise may be beneficial for long-term engagement (57) Need for evidence-based, credible communication of link between increasing physical activity and cognitive health (45)

\section{Key Design Objective \\ Intervention Feature(s)}

Minimising cognitive load

and dependence on technology
- Clear and simple layout, language and navigation procedures - Support provided for cognitive selfregulation (e.g. planning, reminders, prompts for periodic short-term and long-term self-monitoring) - Utilising non-cognitive/non-digital means of sustaining behaviour (habit formation, environmental restructuring)

- Options to print/ save key reference documents/ instructions wherever possible.

- Link to existing non-digital sources of advice/ support where appropriate, including peer/ family support if possible
Positive

framing and promoting immediateterm quality of life benefits

\author{
- Framing activities in terms of \\ benefits for: maintaining \\ independence, enjoyment, strength, \\ balance, pain (especially \\ musculoskeletal), mood, general \\ quality of life. \\ - Referring to benefits for Brain \\ Health rather than reduction in \\ dementia risk
}


Key findings from Literature

Tailoring for different levels of mobility, having optional exercises important/ preferred $(50,55,58,59)$

Need for activities to be simple and safe highly prioritised (41)

\section{Key Design \\ Objective \\ Intervention Feature(s)}

Catering for

highly heterogeneous population (capabilities and preferences)
- Tailoring of content to offer options for levels/ types of activities, with steer towards those with best evidence and most likely to be beneficial for user (based on baseline-assessed need and capability, e.g. activity levels, perceptions of current strength and balance skills)

- Provision of carefully graded activities with very gradual increases from low activity baseline and help with concerns and barriers for those lacking confidence or capability

Monthly development meetings were held with a multi-disciplinary team of coinvestigators including Patient and Public Involvement (PPI) representatives. PPI members played a significant role in ensuring that study and intervention materials were accessible, engaging and persuasive prior to being shared with participants. The wider management team met quarterly and included GPs, specialist clinicians, health psychologists, dementia charity partners and academics with expertise in physical activity, cognitive health and nutrition. Draft intervention materials were frequently shared for comment and iteration.

The following sections outline the methods employed in: 1) planning the intervention's theoretical framework; and 2) the empirical qualitative work conducted to optimise Active Brains. Respective findings/outcomes from each of these processes are reported in the results section.

Planning Active Brains

The planning phase aimed to build the appropriate theory-, evidence- and person-based framework to underpin the Active Brains intervention. This involved: reviewing relevant literature, developing guiding principles, conducting a behavioural analysis and constructing a logic model.

Reviewing relevant literature

We conducted rapid scoping reviews of: 1) physical activity and/or sedentary behaviour interventions, and 2) cognitive training interventions, for older adults with and without cognitive impairment. We aimed to gather evidence about: promising intervention features; relevant contextual factors; and important influences on targeted behaviours. Searches were conducted in Web of Science, March - June 2017 (Additional Table 2). Additional literature was identified through reference-list searching and consultation within our team. Quantitative and qualitative papers were included. Initial searches returned over 9000 matches about cognitive training interventions. Therefore, we focused only on systematic reviews ( $\mathrm{n}=$ 14). Data were extracted about research design, sample size and characteristics, and findings. 
Table 2

Summary of feedback and amendments resulting from think aloud interviews

\begin{tabular}{|c|c|c|c|}
\hline $\begin{array}{l}\text { Active } \\
\text { Brains } \\
\text { section }\end{array}$ & $\begin{array}{l}\text { Summary of issue } \\
\text { identified }\end{array}$ & Example & Change implemented \\
\hline \multirow[t]{2}{*}{$\begin{array}{l}\text { Introductory } \\
\text { content }\end{array}$} & $\begin{array}{l}\text { Worry about continuing } \\
\text { before being reassured } \\
\text { that it would be safe to } \\
\text { try new activities with } \\
\text { various health } \\
\text { conditions/ other } \\
\text { concerns }\end{array}$ & $\begin{array}{l}\text { "I would have it } \\
\text { earlier, yeah, } \\
\text { because the } \\
\text { question in itself is } \\
\text { too sort of set, you } \\
\text { know, it, it's about } \\
\text { increasing activity } \\
\text { gradually rather } \\
\text { than overdoing it. } \\
\text { And I think } \\
\text { something about } \\
\text { that needs to go } \\
\text { before. (P0136) }\end{array}$ & $\begin{array}{l}\text { Although each subsection } \\
\text { contained a section addressing } \\
\text { concerns, it was deemed important } \\
\text { to bring shared concerns forward } \\
\text { to the introductory material so } \\
\text { people felt happy to proceed with } \\
\text { the intervention content }\end{array}$ \\
\hline & $\begin{array}{l}\text { Some pages (and this } \\
\text { applied throughout) } \\
\text { perceived to be a bit } \\
\text { cluttered/ busy with too } \\
\text { much text which some } \\
\text { found off-putting }\end{array}$ & $\begin{array}{l}\text { "I immediately look } \\
\text { at this page and find } \\
\text { it untidy and as a, } \\
\text { not a struggle, but } \\
\text { as a barrier there to } \\
\text { reading it clearly } \\
\text { and understanding } \\
\text { it. I'm struggling to } \\
\text { find what to click to } \\
\text { go to next." (P0245) }\end{array}$ & $\begin{array}{l}\text { Focusing on identified problematic } \\
\text { pages, we edited text to a } \\
\text { minimum. Wherever possible text } \\
\text { was bullet-pointed and only key } \\
\text { messages retained. If important to } \\
\text { keep all text on a page, this was } \\
\text { split over multiple pages where } \\
\text { appropriate. }\end{array}$ \\
\hline \multirow[t]{2}{*}{$\begin{array}{l}\text { Getting } \\
\text { Active }\end{array}$} & $\begin{array}{l}\text { Uncertainty about goal } \\
\text { setting: some seemed } \\
\text { unsure about exactly } \\
\text { what they had set } \\
\text { themselves goals to do } \\
\text { even when goal setting } \\
\text { process complete }\end{array}$ & $\begin{array}{l}\text { "... it's good to have } \\
\text { goals, but I think the } \\
\text { goals need to be } \\
\text { specific. If you're } \\
\text { asking people to } \\
\text { achieve a goal that's } \\
\text { very vague, I don't } \\
\text { think they're } \\
\text { enthusiastic and I } \\
\text { think they give up } \\
\text { and they probably } \\
\text { give up the whole } \\
\text { thing." (P0111) }\end{array}$ & $\begin{array}{l}\text { After revisiting the activity } \\
\text { suggestions made in this section, } \\
\text { it was considered that this } \\
\text { uncertainty was likely to be arising } \\
\text { from the fact that the activity } \\
\text { suggestions and plans that people } \\
\text { could select were a little too broad } \\
\text { - these were amended to more } \\
\text { specific options for people to } \\
\text { choose from }\end{array}$ \\
\hline & $\begin{array}{l}\text { Many mistaking } \\
\text { coloured, bolded text } \\
\text { (to emphasise key } \\
\text { messages in text) for } \\
\text { hyperlinks and } \\
\text { expected links to } \\
\text { additional content }\end{array}$ & $\begin{array}{l}\text { "...anything else } \\
\text { that's in blue, you } \\
\text { think you can click } \\
\text { on it"(P0102) }\end{array}$ & $\begin{array}{l}\text { We removed the colouring of these } \\
\text { parts of text, but retained the } \\
\text { bolding for emphasis. The } \\
\text { minimisation of text to key } \\
\text { messages only also addressed } \\
\text { this issue. }\end{array}$ \\
\hline
\end{tabular}




\begin{tabular}{|c|c|c|c|}
\hline $\begin{array}{l}\text { Active } \\
\text { Brains } \\
\text { section }\end{array}$ & $\begin{array}{l}\text { Summary of issue } \\
\text { identified }\end{array}$ & Example & Change implemented \\
\hline \multirow[t]{2}{*}{$\begin{array}{l}\text { Strength } \\
\text { and } \\
\text { Balance }\end{array}$} & $\begin{array}{l}\text { Concern that } \\
\text { information provided } \\
\text { about the principles of } \\
\text { how strength and } \\
\text { balance exercises } \\
\text { worked (including } \\
\text { information about } \\
\text { specific movements } \\
\text { such as shifting weight } \\
\text { to one side) was } \\
\text { potentially risky if } \\
\text { attempted by those } \\
\text { who were less mobile. }\end{array}$ & $\begin{array}{l}\text { "...if you have } \\
\text { somebody with poor } \\
\text { balance, it's just } \\
\text { trying to ensure, how } \\
\text { do you ensure that } \\
\text { someone who } \\
\text { shouldn't really be } \\
\text { standing on one leg } \\
\text { doesn't stand on one } \\
\text { leg, despite what } \\
\text { you've said about } \\
\text { being safe." (P0106) }\end{array}$ & $\begin{array}{l}\text { The text in this section was } \\
\text { reframed to describe the } \\
\text { underlying principles of the } \\
\text { exercises without reference to } \\
\text { specific examples that may be } \\
\text { dangerous if attempted by } \\
\text { someone with poorer } \\
\text { mobility/balance. Instead it now } \\
\text { talks about how the suggested } \\
\text { activities allow practice of } \\
\text { movements to expand individuals } \\
\text { 'comfort zone' in terms of } \\
\text { movements they can make. }\end{array}$ \\
\hline & $\begin{array}{l}\text { Disagreement with } \\
\text { advice that if users are } \\
\text { unsure about whether } \\
\text { suggested activities are } \\
\text { suitable for them, then } \\
\text { to consult with their GP } \\
\text { - users not } \\
\text { comfortable with the } \\
\text { idea of taking up GP } \\
\text { time with these types } \\
\text { of queries. }\end{array}$ & $\begin{array}{l}\text { "It's... I always find } \\
\text { this information } \\
\text { about checking with } \\
\text { your doctor before } \\
\text { you start interesting, } \\
\text { because I very... well, } \\
\text { I say that. I very } \\
\text { seldom make plans } \\
\text { to go and visit the } \\
\text { doctor. And I } \\
\text { certainly wouldn't } \\
\text { regarding this, I } \\
\text { think." (P0105) }\end{array}$ & $\begin{array}{l}\text { Revised to reassure users that the } \\
\text { activities recommended were } \\
\text { nothing outside of routine } \\
\text { movements made in day-to-day } \\
\text { life and that they were likely the } \\
\text { best judge of whether they could } \\
\text { safely/comfortably do these Also } \\
\text { encouraged to discuss with those } \\
\text { who knew them well, and only } \\
\text { seek advice from GP for serious } \\
\text { concerns. }\end{array}$ \\
\hline $\begin{array}{l}\text { Breaks } \\
\text { from Sitting }\end{array}$ & $\begin{array}{l}\text { Some activity plans } \\
\text { about how to } \\
\text { implement } \\
\text { recommendations } \\
\text { deemed unrealistic or } \\
\text { 'silly' - e.g. purposely } \\
\text { leaving objects upstairs } \\
\text { that you know you will } \\
\text { need downstairs to } \\
\text { increase steps around } \\
\text { the house }\end{array}$ & $\begin{array}{l}\text { "Leave your bedtime } \\
\text { book on the kitchen } \\
\text { table. I don't get that } \\
\text { one. How does that } \\
\text { work? You're just } \\
\text { gonna pick it up } \\
\text { when you're } \\
\text { downstairs and } \\
\text { carry it to the } \\
\text { bedroom and then } \\
\text { bring it back down..." } \\
\text { (P0101) }\end{array}$ & $\begin{array}{l}\text { Such examples were removed or } \\
\text { replaced. New suggestions } \\
\text { focused on ways people could: } \\
\text { add some movement in to times } \\
\text { they might be completely } \\
\text { sedentary (e.g. leg raises whilst } \\
\text { watching TV); add more } \\
\text { movement into standing or mostly } \\
\text { sedentary times (e.g. marching on } \\
\text { the spot whilst brushing teeth) }\end{array}$ \\
\hline
\end{tabular}

Some activities to identify common

These suggestions

times/places for sitting, were not considered either: a) a suitable target for change (i.e. at doctors surgery), or b) an activity that they would actually do sitting down (e.g. brushing teeth) were removed 


\begin{tabular}{|c|c|c|c|}
\hline $\begin{array}{l}\text { Active } \\
\text { Brains } \\
\text { section }\end{array}$ & $\begin{array}{l}\text { Summary of issue } \\
\text { identified }\end{array}$ & Example & Change implemented \\
\hline \multirow[t]{2}{*}{$\begin{array}{l}\text { Brain } \\
\text { Training }\end{array}$} & $\begin{array}{l}\text { The wording of some } \\
\text { True/False quiz } \\
\text { questions was } \\
\text { considered confusing, } \\
\text { e.g. one stated that the } \\
\text { purpose of brain } \\
\text { training games was to } \\
\text { keep improving your } \\
\text { score. If/when people } \\
\text { answered 'True', they } \\
\text { were surprised when } \\
\text { their answer wasn't } \\
\text { considered correct }\end{array}$ & $\begin{array}{l}\text { "Yeah, well that's, } \\
\text { that automatically } \\
\text { to me should be true } \\
\text { but it's, you } \\
\text { explaining it, but it's } \\
\text { not clear. The point } \\
\text { of brain training is } \\
\text { for you to get better, } \\
\text { any training is to get } \\
\text { better, but it said it's } \\
\text { false." (P0104) }\end{array}$ & $\begin{array}{l}\text { To ensure participants remained } \\
\text { engaged with these quiz questions } \\
\text { and did not take away the wrong } \\
\text { message, wording/ feedback was } \\
\text { revisited and amended where } \\
\text { necessary. In this example, the } \\
\text { feedback was clarified to state } \\
\text { that whilst a good aim to try and } \\
\text { improve scores, the important } \\
\text { factor is continuing to practice } \\
\text { these games whether or not your } \\
\text { score improves }\end{array}$ \\
\hline & $\begin{array}{l}\text { Given different } \\
\text { structure of the Brain } \\
\text { Training section } \\
\text { compared to other } \\
\text { sections, a page } \\
\text { preceding the Brain } \\
\text { Training menu } \\
\text { explained how to use } \\
\text { menu page, but this } \\
\text { created confusion }\end{array}$ & $\begin{array}{l}\text { "It's a bit confusing, } \\
\text { this one. I don't } \\
\text { know quite why. } \\
\text { This bit I think might } \\
\text { be more beneficial } \\
\text { on the next page?" } \\
\text { (J0112) }\end{array}$ & $\begin{array}{l}\text { This page was removed and the } \\
\text { navigation around the Brain } \\
\text { Training menu pages was revised } \\
\text { to ensure that it was clear how } \\
\text { users could access each element } \\
\text { of the Brain Training module - } \\
\text { most importantly the link to the } \\
\text { Brain Training games. }\end{array}$ \\
\hline
\end{tabular}

Development of Guiding Principles

Guiding principles aim to maximise the acceptability of an intervention amongst target users and, therefore, to enhance engagement and effectiveness. Each guiding principle comprises: 1) a design objective outlining a user/context-specific behavioural need, issue or challenge; and 2) intervention features that address the design objective (27). To draft provisional guiding principles, we drew on our understanding of target users obtained from the scoping reviews and from our research team, including PPI members. These guiding principles were iteratively developed as new data emerged, e.g., from the behavioural analysis and qualitative interviews.

Developing Active Brains programme theory

A programme theory explicitly describes how an intervention is expected to achieve its intended outcomes, and the anticipated mechanisms through which this occurs (29). The behavioural analysis and logic model contributed to this process.

Behavioural Analysis

The behavioural analysis aimed to identify behaviours to be targeted by Active Brains and their potential barriers and facilitators. We recorded relevant evidence from scoping reviews, team expertise and later qualitative interviews into a table, and mapped behaviours and potential barriers and facilitators onto 
constructs from the Behaviour Change Wheel (BCW: 30) and Theoretical Domains Framework (TDF: 31). This allowed clear description of the intervention processes and components, including behavioural domains to be targeted, intervention functions to address barriers and facilitators, and Behaviour Change Techniques (BCTs: 32) to deliver these functions.

The Active Brains intervention logic model

In line with Medical Research Council (MRC) guidance (33), we constructed a logic model to diagrammatically represent the expected mechanisms of action of Active Brains. This drew on the scoping reviews, team expertise, guiding principles and behavioural analysis.

Optimising Active Brains

The optimisation phase aimed to seek feedback on draft intervention material, and to explore the acceptability and feasibility of the digital content and functionality amongst older adults with higher and lower levels of cognitive performance. Due to the vast quantity of relevant literature available to inform initial content development, primary qualitative research was delayed in favour of planning and drafting initial content (34). This allowed us to seek feedback sooner, and meant we could still explore target users' experiences to inform changes required.

Think-aloud interviews

Forty-one adults $(22$ female, mean age $=70.5$ years, range $61-80$ ) were recruited from GP practices across the South of England and from Join Dementia Research (JDR; an online database for matching UK community-dwelling individuals to relevant studies) to take part in think-aloud interviews. We employed purposive sampling whereby we attempted to obtain maximum variation in terms of gender, age, education level, socio-economic status and cognitive performance score. Participants were excluded if they were already reasonably physically active (score $>30$ on Godin Leisure Time Exercise Questionnaire (35)), had diagnosed dementia, a severe uncontrolled mental health condition, or terminal illness. As part of the screening process, participants completed a brief cognitive assessment (online Baddeley verbal reasoning task (36)), which determined whether they were identified as a participant with 'lower cognitive performance' or 'higher cognitive performance'. Lower cognitive performance was defined as a score falling more than one standard deviation below the 'normative score', determined by a database of scores from a large $(n>10,000)$ pre-existing cohort of older adults. Although this single test was not indicative of cognitive impairment, this categorization enabled us to sample views from those with higher $(n=20)$ and lower levels $(n=21)$ of cognitive performance.

Each participant took part in one think-aloud interview in which they worked through the prototype Active Brains intervention with an interviewer. The participant was encouraged to vocalise all immediate thoughts and feelings toward the content. This allowed insight into target users' immediate reactions to elements of the intervention. As it was unfortunately not possible for participants to access the brain training games, we provided screenshots to show the types of task this involved. These existing games have been extensively used in ongoing cohort studies, and study investigators report them being well 
liked and engaged with. Following the think-aloud interview, there were semi-structured interview questions about participants' general views of the intervention: what they liked/disliked, found helpful/difficult, would like to change etc. All interviews were audio-recorded and transcribed verbatim.

Data were analysed to understand user views on the intervention content and inform potential changes. We collated all positive and negative comments pertaining to specific intervention elements into a 'table of changes' (Additional Table 3). After discussing the frequency and significance of positive and negative comments, we coded the importance of possible changes by deciding whether any amendment was likely to enhance the persuasiveness, acceptability and likelihood of changing behaviour (37). For example, we considered: whether multiple people provided the same feedback; if the potential change aligned with our guiding principles and/or expert opinion; and whether theory and/or evidence suggested the change would make the desired behaviour more likely. We prioritised changes by their relevance to behaviour change or ability to prevent disengagement. If changes were low-priority, they were implemented only if relatively quick and easy. Interviews continued alongside this analysis to allow iterative modification of content prior to the next batch of interviews. Once it seemed that no further important changes were required, we considered that data saturation had been reached (37).

Longitudinal qualitative feasibility study

This second element of the qualitative work commenced once the majority of prioritised modifications to the prototype had been made. Eligibility, sampling and recruitment procedures were the same as in the think-aloud interviews. Eighteen older adults (12 female, mean age $=69.1$ years, range 62-76) took part, seven of whom had participated in the think-aloud interviews. The eighteen participants were classified evenly across the lower and higher cognitive performance groups ( $n=9$ in each group).

Participants were invited to use Active Brains for three weeks (timings were 'sped-up' to allow access to all sections) and were given a diary to keep notes about their experiences. Participants took part in one semi-structured interview each during this time. The interview asked participants about their experiences of engaging with the intervention and any relevant activities they tried. They were prompted to discuss certain features or elements that they particularly liked and/or found helpful or disliked and/or found difficult. Towards the end, there were questions about participants' perceptions and understandings of cognitive health, and their views on social support for engaging in new activities. All interviews were audio-recorded and transcribed verbatim.

All data were tabulated and analysed as described in the think-aloud study. In addition, inductive thematic analysis (38) was conducted on the data from the second part of the interview examining perceptions and understandings of cognitive health and social support.

\section{Results}

Planning Active Brains

Reviewing relevant literature 
Given the wealth of existing reviews on the topics of interest, the findings were not formally synthesised for write-up. However, several findings pertinent to our research questions are summarised in Table 1, which also illustrates how they informed intervention guiding principles. There was no substantial evidence that the intervention's physical activity recommendations should differ for older adults with $\mathrm{MCl} / \mathrm{AACD}$ compared to a general older-adult population. The cognitive training intervention evidence suggested training multiple cognitive-domains to be the optimum choice for both cognitively-healthy older adults and those with cognitive impairment (e.g. 39, 40). Regarding physical activity interventions, those with and without cognitive impairment shared similar attitudes towards physical activity, and recognised similar barriers (e.g. remembering, social isolation), facilitators (e.g. accessibility of activity options, simple activities) and preferred activities (e.g. walking) $(41,42)$. There was only a small amount of evidence about intervention features that may be acceptable and engaging for both groups.

Acceptable intervention features amongst those with cognitive impairment often overlapped with those frequently used in interventions for older adults in general (e.g. planning features; 43). Otherwise, there was little evidence about whether engagement with intervention features was likely to differ between groups, so we aimed to explore this within our primary qualitative work.

Development of Guiding Principles

The finalised Active Brains guiding principles (Table 1) were: minimizing cognitive load and dependence on technology; positive framing and promoting immediate-term quality of life benefits; and catering for heterogeneous preferences and capabilities.

Developing Active Brains programme theory

Behavioural Analysis

The full behavioural analysis is presented in Additional Table 4. Active Brains targeted nine behaviours: initial engagement with the online intervention; increasing physical activity; reducing sedentary behaviour; uptake of strength and balance activities; uptake of brain training; healthy changes to eating behaviours; reviewing behaviours and revising goals; integration of recommended activities into daily routines, and; maintaining engagement with the online intervention. These behaviours were further broken down into 19 sub-behaviours required to enact each behaviour. Mapping these behaviours, their determinants, and intervention features onto the BCW and TDF illustrates that Active Brains employs 36 BCTs to deliver seven intervention functions (modelling, education, persuasion, training, enablement, environmental restructuring, incentivisation) to target thirteen behavioural domains (intentions, optimism, emotion, knowledge, skills, beliefs about consequences, beliefs about capabilities, goals, social influences, environmental context and resources, reinforcement, memory, attention and decision processes and behavioural regulation).

The Active Brains intervention logic model

A summary version of the Active Brains logic model is shown in Fig. 2. Additional Fig. 1 shows the full version with intervention processes mapped on to BCW, TDF and BCTs. The Active Brains digital intervention comprises three online modules that become available sequentially: 'Active Lives' (physical 
activity) is available immediately; 'Brain Training' (cognitive training) is available after 4 weeks; and 'Eat for Health' (healthy eating) is available after 8 weeks. 'Active Lives' is further divided into three submodules: 'Getting Active', 'Strength and Balance' and 'Breaks from Sitting' with recommendations about which to start with tailored to users' baseline activity and capability. Within each module, users can access: information addressing common concerns, instruction about recommended activities, goal setting and review for chosen activities, and tailored motivational feedback on progress. Reminder emails are sent to motivate users to continue with their activities and to encourage them to revisit online content. Additional support from a central facilitator (for one arm of Active Brains trial) comprises up to three 10minute phone calls at two-week intervals, plus additional email support if required. This can be used to discuss behavioural changes participants are attempting, and to support them with use of the online intervention content. The facilitator employs the CARE (Congratulate, Ask, Reassure, Encourage) approach to provide support in a broadly standardised format (44). After seven months, the Active Brains 'booster section' allows users access to additional resources for embedding recommended activities into daily life. It also introduces the brain training 'boosters' to maintain the benefits of the initial intensive training period.

Optimising Active Brains

The findings of the qualitative work are described below. These fed back into ongoing iteration of the guiding principles, and behavioural analysis and also informed required intervention changes.

Think-aloud interviews

Table 2 summarises feedback and the resulting changes implemented. Feedback on the Active Brains prototype was encouraging. Users were particularly positive about what they considered to be more novel activities including strength and balance training, and brain training games. Less positive feedback included sections where users found navigation confusing, a lack of specificity surrounding physical activity goals, and a desire to address health-related concerns earlier. We analysed feedback for differences between those with lower and higher cognitive performance scores to determine whether different intervention features or characteristics may be more engaging or desirable for those with lower cognitive performance. There was no evidence of any substantive differences.

Longitudinal qualitative feasibility study

Part one: Table of changes analysis

Collating feedback into a second table of changes confirmed that the amendments based on the initial think-aloud interviews were well received, with the original issues no longer being raised. In general, there were a smaller number of negative comments about the intervention content, but a few remaining points were identified and addressed (Table 3). There were no substantial differences in the views expressed by individuals with higher and lower levels of cognitive performance. 
Table 3

Summary of feedback and amendments resulting from longitudinal interviews

\begin{tabular}{|c|c|c|}
\hline Summary of issue identified & Example & Change implemented \\
\hline $\begin{array}{l}\text { Some voiced opinion that they felt } \\
\text { physical activity content wasn't } \\
\text { relevant to them as they perceived } \\
\text { themselves to already be } \\
\text { physically active (despite not } \\
\text { meeting exclusion criteria for } \\
\text { existing high levels of physical } \\
\text { activity) }\end{array}$ & $\begin{array}{l}\text { "For me, it was the actual } \\
\text { activities, the actual physical } \\
\text { bits, weren't terribly } \\
\text { challenging." (P0146) }\end{array}$ & $\begin{array}{l}\text { Additional messages added in to } \\
\text { introductory and early physical activity } \\
\text { content to emphasise that even those } \\
\text { who are already active can use content } \\
\text { to help them increase activity, and to } \\
\text { stress importance of continuing with/ } \\
\text { increasing activities they already do } \\
\text { and enjoy. }\end{array}$ \\
\hline $\begin{array}{l}\text { A few suggestions that it would be } \\
\text { useful to have more explicit } \\
\text { suggestions about ways to stay } \\
\text { motivated with making } \\
\text { behavioural changes - } \\
\text { particularly about how to use } \\
\text { social support to do so }\end{array}$ & $\begin{array}{l}\text { "The one thing I think you } \\
\text { could do a bit on is finding the } \\
\text { incentive to do all these things, } \\
\text { so that we've got to do them to } \\
\text { keep going, but you tend to put } \\
\text { them off because you're doing } \\
\text { other things at the time." } \\
\text { (P0265) }\end{array}$ & $\begin{array}{l}\text { Extra pages added to give examples of } \\
\text { motivational strategies, including ways } \\
\text { to involve others (e.g. weekly step- } \\
\text { count competition with friends/family) } \\
\text { tand activities to boost motivation (e.g. } \\
\text { 'Reasons to be Active' card). }\end{array}$ \\
\hline $\begin{array}{l}\text { Some perceived healthy eating } \\
\text { content to be largely in line with } \\
\text { what they were already doing. } \\
\text { Furthermore, expert advice from } \\
\text { within the team recommended } \\
\text { placing greater emphasis on the } \\
\text { 'foods for brain health' as } \\
\text { novel/interesting element. }\end{array}$ & $\begin{array}{l}\text { "I read it through with interest } \\
\text { and I thought: Oh, well, I do } \\
\text { that; I eat that. I agree with all } \\
\text { of that and that's what I do; } \\
\text { but there was nothing in there } \\
\text { that I felt that I didn't already } \\
\text { do." (P0250) }\end{array}$ & $\begin{array}{l}\text { Restructure of the healthy eating } \\
\text { content so that the initial information } \\
\text { and goal setting centres around } \\
\text { specific foods beneficial for cognitive } \\
\text { health, with additional more general } \\
\text { healthy eating advice presented after } \\
\text { this. }\end{array}$ \\
\hline
\end{tabular}

Part two: inductive thematic analysis

The inductive thematic analysis generated three overarching themes, comprising several subthemes.

These were: 1)'knowledge and understanding of brain health', including subthemes 'the meaning of brain health', 'perceived availability of information about brain health' and 'knowledge of determinants of brain health'; 2) 'motivators and barriers', including the subthemes 'motivations for achieving/maintaining good brain health', 'motivators for engaging in helpful behaviours', and 'barriers to engaging in helpful behaviours'; and finally 3) 'the role of social support' including subthemes 'desirability of social support' and 'motivational mechanisms of social support'. Each theme is briefly summarised with illustrative quotes from the data. These findings helped to refine the intervention guiding principles and behavioural analysis.

Knowledge and understanding of brain health

This theme suggests that, for older adults, 'good brain health' is largely about maintaining independence and remaining able to do the activities one wishes to do. More than half of participants also discussed retention of specific cognitive skills such as good memory and decision-making.

"If you've got good brain health, then you can carry on with your daily life: cooking, managing your finances, managing your social life - you know, day-to-day things, really." (P0229, female, 68, higher cognitive performance)

A large proportion of individuals felt that, whilst information about cognitive health and how to protect it is available, it often requires one to actively look for it. Many also mentioned the availability of information about body health, but not necessarily about brain health. 
"So you do need to know about it. But you have to make the effort to either read a newspaper or look at the news, or get your brain active yourself." (P0265, female, 69, lower cognitive performance)

Despite this, nearly three-quarters of participants named typically promoted strategies for maintaining cognitive health, such as brain training activities and puzzles. Half of participants also acknowledged the role of health-related behaviours, such as physical activity, in maintaining cognitive health.

Motivators and barriers

Two different types of motivation were identified within participants' accounts. The first were motivations to maintain good brain health in order to avoid cognitive decline and its anticipated negative consequences, such as loss of independence, poor quality of life, and interference with relationships. This was often accompanied by accounts of friends or family with dementia and their strong wish to avoid this.

"It's a tremendous thing, for me anyway, because I've seen other people go through it. I don't want to, [...] It is frustrating for other people as well as for yourself. I think it's important not just for you, but it's also important for the rest of the family, and to be able to pass the memories on as well." (P0225, female, 65, lower cognitive performance)

The second type of motivation related to factors that encouraged individuals to engage in behaviours important for maintaining cognitive health. The overwhelming sentiment was that enjoyment is the main motivator. Even when individuals acknowledged that behaviours were beneficial for brain health, this seemed an 'added bonus' rather than the primary motivator.

"...yeah, you know, I do a lot of things like maths games. And crosswords and stuff like that every day, so I don't know if that actually helps but I just find them interesting." (P0138, male, 70, higher cognitive performance)

Barriers to engaging in activities to support cognitive health were not discussed extensively, but the most common difficulty mentioned was managing other health conditions.

"I'm quite hampered with physical activity because I've got arthritis and am registered disabled so, to be honest, physical activity is so difficult for me. That's where these exercises come in, really and it's mostly what I can do." (P0261, male, 62, higher cognitive performance)

The role of social support

Participants who discussed involving others in healthy lifestyle activities mentioned several mechanisms through which this provided motivation for beginning and maintaining activities. This included creation of action plans with others, being accountable to others and sharing encouragement and new ideas. "I think, if you're going swimming or something once a week, it's nice if someone says, 'Are you ready to go?' 'Shall we go today?' rather than you think: Oh, do I really want to go today? If there's two of you or three of you wanting to go, you encourage each other." (P0229, female, 68, higher cognitive performance) However, it was widely acknowledged that individuals' preferences and circumstances determine whether involvement of others is possible, or even desirable. More than half of participants expressed that they would be happy (or sometimes prefer) to do such activities alone.

"I'm quite happy with my own company. I mean, I enjoy doing things with other people, and I go to yoga and I get on with everybody there, and I've got quite a few friends that go, but I would go whether they went or not." (P0129, female, 67, lower cognitive performance). 


\section{Discussion}

This paper presents a theory-, evidence- and person-based approach to intervention development that could be applied across numerous behaviour change contexts. We have provided a systematic account of how and why the intervention took its current form, and how it is expected to work. In doing so, we have provided valuable transferable insights into the acceptability of a digital multi-domain intervention to reduce cognitive decline amongst older adults with a range of cognitive performance abilities.

This study has provided preliminary empirical evidence that a digital multi-domain behaviour change intervention appears acceptable and engaging amongst UK community-dwelling older adults. Our findings reinforce and extend existing literature. Importantly, there were no substantive differences between those with higher and lower cognitive performance scores regarding their preferences or requirements for the Active Brains intervention, or their ability and willingness to engage with the digital intervention. This finding reinforced our judgement (informed by the initial literature review) that the Active Brains digital intervention was accessible and engaging for people with lower cognitive performance scores and did not need to be tailored according to cognitive status. This also aligns with previous findings $(39,40)$, suggesting that the same activity recommendations might be suitable for those with and without cognitive impairment, given that they appear to share similar motivations, barriers, and attitudes. Our findings extend limited evidence about preferred intervention features (43), by demonstrating that those suitable for a general older adult population appear engaging and acceptable for those with lower cognitive performance scores too.

Similarly, our findings about older adults' perceptions of cognitive health generally align with the existing literature: maintaining independence (45) and enjoyment of activities (46) seem key motivators amongst this group. We found that an awareness of, and desire to avoid, the consequences of dementia also seemed to motivate cognition-protective behaviours, whilst other health conditions arose as a possible barrier. Additionally, our findings extend understandings about the value of social support. Whilst they concur that, for many, social support is an important motivator of behaviours such as physical activity (47), they reveal that for many it is not considered necessary or desirable. This has important implications for offering social support within interventions, i.e. it should be available but not a compulsory element. Furthermore, as social support didn't appear to be a primary motivation for engagement with the intervention, this lends additional support to the potential feasibility and acceptability of a digital-delivery format. Overall, our findings largely concur with the literature that informed our preliminary intervention guiding principles and behavioural analysis and so largely confirmed the priorities for intervention functions and features. The qualitative data also provide valuable, detailed feedback that has informed the optimisation of Active Brains to maximise the likelihood of intervention engagement and effectiveness.

This paper addresses numerous calls to more clearly articulate the intervention development process, and the resulting intervention's expected mechanisms of action (33). It is important to test these mechanisms to provide new evidence about behavioural determinants and the most effective intervention functions to 
target them (33), particularly in multi-domain interventions. This information enables advancement of theoretical understandings of behaviour change in diverse contexts (48). The extensive qualitative research is a further strength of this rigorous intervention development process. The qualitative interviews provided in-depth understanding of target users' preferences and life-context to maximise acceptability. These participants represent a wide-ranging community-based group, purposively sampled from JDR as well as primary care. As participants' understandings of cognitive health were sought during the period that they had access to Active Brains, their views could have been influenced by their experience of the intervention. However, these questions explored perceptions of cognitive health in a broad sense rather than how they related to specific intervention content. Indeed, participants' responses more often involved accounts of their own beliefs and experiences than reference to Active Brains.

With the development of Active Brains now complete, the next step is a feasibility trial $(n=360$, in progress) to test the intervention and trial procedures. A fully powered trial $(n=20,000)$ then aims to determine whether the Active Brains intervention can successfully reduce the incidence of dementia amongst older adults over a 5-year period. The systematic development process provides scope for later process evaluation to test the mechanisms through which the intervention is expected to work.

\section{Conclusion}

This study has begun to address the need for a rigorously-developed, low-cost, multi-domain behaviour change intervention for maintaining older adults' cognitive health. It presents the theory-, evidence- and person-based framework that arose from the planning of the intervention, as well as the primary qualitative evidence that helped to optimise acceptability of intervention content and functionality. As well as facilitating optimisation of intervention content, the qualitative data contribute a greater understanding of older adults' perceptions of brain health, and the barriers and facilitators to engaging in preventative behaviours. In doing so, this study has provided evidence that a digitally-delivered intervention with minimal support appears acceptable and potentially engaging to older adults with higher and lower levels of cognitive performance.

\section{Abbreviations}

(in order of appearance)

WHO: World Health Organisation

MCl: Mild Cognitive Impairment

AACD: Age-Associated Cognitive Decline

PPI (representative): Public and Patient Involvement (representative)

BCW: Behaviour Change Wheel

Page $18 / 26$ 
TDF: Theoretical Domains Framework

BCTs: Behaviour Change Techniques

MRC: Medical Research Council

JDR: Join Dementia Research

CARE (approach): Congratulate, Ask, Reassure, Encourage (approach)

\section{Declarations}

Ethics approval and consent to participate

Full ethical approval was obtained from the University of Southampton (sponsor) and National Research Ethics Service (IRAS number: 228584; REC Ref: 17/SC/0463) prior to any recruitment or data collection occurring. Fully informed (online) written consent was obtained from all participants.

Consent for publication

Not applicable

Availability of data and materials

The datasets used and/or analysed during the current study are available from the corresponding author on reasonable request. Further examples and extracts from data/analysis are available in additional files.

Competing interests

The authors declare that they have no competing interests.

Funding

This work was supported by the National Institute for Health Research (NIHR) under its Programme Grants for Applied Research (Reference Number RP-PG-0615-20014). The views expressed are those of the author(s) and not necessarily those of the NIHR or the Department of Health and Social Care.

The Active Brains intervention was developed using LifeGuide software, which was partly funded by the NIHR Southampton Biomedical Research Centre (BRC).

Authors' contributions

RE and $L Y$ led the intervention development and optimisation, $P L$ and $L Y$ led the research programme and RE drafted this paper. AMi, AMu and BS conducted and summarised the scoping review work. RE, SP, KS, FM, JS-B, JD-D, KB, VH, EG, MW, CH, AF, NM, SG, TK, BG, RP, TS, JN, PL and LY all contributed to the design and iterative development of intervention content and study procedures. RE, FM, KS, MW, J-SB, SP, 
EG, AF and AMi collected and/or analysed qualitative data. All co-authors assisted with and contributed to the evaluation and reporting of the intervention development in this paper.

Acknowledgements

Not applicable

\section{References}

1. World Health Organisation (WHO). Global action plan on the public health response to dementia 2017-2025. https://www.who.int/mental_health/neurology/dementia/action_plan_2017_2025/en/; 2017.

2. Ritchie K, Artero S, Touchon J. Classification criteria for mild cognitive impairment A populationbased validation study. Neurology. 2001;56(1):37-42.

3. Petersen RC. Mild Cognitive Impairment. Continuum (Minneap Minn). 2016;22(2 Dementia):404-18.

4. Mitchell AJ, Shiri-Feshki M. Rate of progression of mild cognitive impairment to dementia-metaanalysis of 41 robust inception cohort studies. Acta Psychiatrica Scandinavica. 2009;119(4):252-65.

5. Alzheimer's Diesease International. World Alzheimer Report 2018. The state of the art of dementia research: New frontiers. https://www.alz.co.uk/research/WorldAlzheimerReport2018.pdf; 2018.

6. Mansbach WE, Mace RA. Predicting Functional Dependence in Mild Cognitive Impairment: Differential Contributions of Memory and Executive Functions. The Gerontologist. 2018;59(5):92535.

7. Livingston G, Sommerlad A, Orgeta V, Costafreda SG, Huntley J, Ames D, et al. Dementia prevention, intervention, and care. The Lancet. 2017;390(10113):2673-734.

8. Lafortune L, Martin S, Kelly S, Kuhn I, Remes O, Cowan A, et al. Behavioural Risk Factors in Mid-Life Associated with Successful Ageing, Disability, Dementia and Frailty in Later Life: A Rapid Systematic Review. PloS one. 2016;11(2):e0144405.

9. Santos-Lozano A, Pareja-Galeano H, Sanchis-Gomar F, Quindos-Rubial M, Fiuza-Luces C, CristiMontero C, et al. Physical Activity and Alzheimer Disease: A Protective Association. Mayo Clinic proceedings. 2016;91(8):999-1020.

10. Tangney CC, Li H, Wang Y, Barnes L, Schneider JA, Bennett DA, et al. Relation of DASH-and Mediterranean-like dietary patterns to cognitive decline in older persons. Neurology. 2014;83(16):1410-6.

11. Corbett A, Owen A, Hampshire A, Grahn J, Stenton R, Dajani S, et al. The effect of an online cognitive training package in healthy older adults: an online randomized controlled trial. Journal of the American Medical Directors Association. 2015;16(11):990-7.

12. Vaughan $S$, Wallis $M$, Polit $D$, Steele M, Shum D, Morris $N$. The effects of multimodal exercise on cognitive and physical functioning and brain-derived neurotrophic factor in older women: a randomised controlled trial. Age Ageing. 2014;43(5):623-9. 
13. Panza GA, Taylor BA, MacDonald HV, Johnson BT, Zaleski AL, Livingston J, et al. Can exercise improve cognitive symptoms of Alzheimer's disease? Journal of the American Geriatrics Society. 2018;66(3):487-95.

14. Valls-Pedret C, Sala-Vila A, Serra-Mir M, Corella D, de la Torre R, Martínez-González MÁ, et al. Mediterranean diet and age-related cognitive decline: a randomized clinical trial. JAMA internal medicine. 2015;175(7):1094-103.

15. Reijnders J, van Heugten C, van Boxtel M. Cognitive interventions in healthy older adults and people with mild cognitive impairment: A systematic review. Ageing Research Reviews. 2013;12(1):263-75.

16. Savulich G, Piercy T, Fox C, Suckling J, Rowe JB, O’Brien JT, et al. Cognitive training using a novel memory game on an iPad in patients with amnestic mild cognitive impairment (aMCl). International Journal of Neuropsychopharmacology. 2017;20(8):624-33.

17. Ngandu T, Lehtisalo J, Solomon A, Levälahti E, Ahtiluoto S, Antikainen R, et al. A 2 year multidomain intervention of diet, exercise, cognitive training, and vascular risk monitoring versus control to prevent cognitive decline in at-risk elderly people (FINGER): a randomised controlled trial. The Lancet. 2015;385(9984):2255-63.

18. Andrieu S, Guyonnet S, Coley N, Cantet C, Bonnefoy M, Bordes S, et al. Effect of long-term omega 3 polyunsaturated fatty acid supplementation with or without multidomain intervention on cognitive function in elderly adults with memory complaints (MAPT): a randomised, placebo-controlled trial. The Lancet Neurology. 2017;16(5):377-89.

19. Moll van Charante EP, Richard E, Eurelings LS, van Dalen JW, Ligthart SA, van Bussel EF, et al. Effectiveness of a 6-year multidomain vascular care intervention to prevent dementia (preDIVA): a cluster-randomised controlled trial. Lancet. 2016;388(10046):797-805.

20. Murray E, Hekler EB, Andersson G, Collins LM, Doherty A, Hollis C, et al. Evaluating Digital Health Interventions: Key Questions and Approaches. American journal of preventive medicine. 2016;51(5):843-51.

21. Aalbers T, Qin L, Baars MA, de Lange A, Kessels RP, Olde Rikkert MG. Changing Behavioral Lifestyle Risk Factors Related to Cognitive Decline in Later Life Using a Self-Motivated eHealth Intervention in Dutch Adults. J Med Internet Res. 2016;18(6):e171.

22. Tennant B, Stellefson M, Dodd V, Chaney B, Chaney D, Paige S, et al. eHealth Literacy and Web 2.0 Health Information Seeking Behaviors Among Baby Boomers and Older Adults. J Med Internet Res. 2015;17(3):e70.

23. Fang ML, Canham SL, Battersby L, Sixsmith J, Wada M, Sixsmith A. Exploring Privilege in the Digital Divide: Implications for Theory, Policy, and Practice. The Gerontologist. 2018;59(1):e1-e15.

24. O'Cathain A, Croot L, Sworn K, Duncan E, Rousseau N, Turner K, et al. Taxonomy of approaches to developing interventions to improve health: a systematic methods overview. Pilot and feasibility studies. 2019;5(1):41.

25. Craig P, Dieppe P, Macintyre S, Michie S, Nazareth I, Petticrew M. Developing and evaluating complex interventions: the new Medical Research Council guidance. 2013. 
26. Kok G, Shaalma H. Using Theory in Psychological Interventions. In: Michie S, Abraham C, editors. Health Psychology in Practice. Oxford: Blackwell; 2004. p. 203-9.

27. Yardley L, Morrison L, Bradbury K, Muller I. The person-based approach to intervention development: application to digital health-related behavior change interventions. Journal of medical Internet research. 2015;17(1):e30.

28. Evans RE, Craig P, Hoddinott P, Littlecott H, Moore L, Murphy S, et al. When and how do 'effective' interventions need to be adapted and/or re-evaluated in new contexts? The need for guidance. Journal of Epidemiology and Community Health. 2019;73(6):481-2.

29. Funnell SC, Rogers PJ. Purposeful program theory: Effective use of theories of change and logic models: John Wiley \& Sons; 2011.

30. Michie S, Van Stralen MM, West R. The behaviour change wheel: a new method for characterising and designing behaviour change interventions. Implementation science. 2011;6(1):42.

31. Cane J, O'Connor D, Michie S. Validation of the theoretical domains framework for use in behaviour change and implementation research. Implementation science. 2012;7(1):37.

32. Michie S, Richardson M, Johnston M, Abraham C, Francis J, Hardeman W, et al. The behavior change technique taxonomy (v1) of 93 hierarchically clustered techniques: building an international consensus for the reporting of behavior change interventions. Annals of behavioral medicine. 2013;46(1):81-95.

33. Moore GF, Audrey S, Barker M, Bond L, Bonell C, Hardeman W, et al. Process evaluation of complex interventions: Medical Research Council guidance. BMJ : British Medical Journal. 2015;350:h1258.

34. Band R, Bradbury K, Morton K, May C, Michie S, Mair FS, et al. Intervention planning for a digital intervention for self-management of hypertension: a theory-, evidence- and person-based approach. Implementation Science. 2017;12(1):25.

35. Godin G, Shephard R. Godin leisure-time exercise questionnaire. Med Sci Sports Exerc. 1997;29(6):368.

36. Baddeley AD. A 3 min reasoning test based on grammatical transformation. Psychonomic Science. 1968;10(10):341-2.

37. Bradbury K, Morton K, Band R, van Woezik A, Grist R, McManus RJ, et al. Using the Person-Based Approach to optimise a digital intervention for the management of hypertension. PLOS ONE. 2018;13(5):e0196868.

38. Braun V, Clarke V. Using thematic analysis in psychology. Qualitative research in psychology. 2006;3(2):77-101.

39. Coyle H, Traynor V, Solowij N. Computerized and Virtual Reality Cognitive Training for Individuals at High Risk of Cognitive Decline: Systematic Review of the Literature. The American Journal of Geriatric Psychiatry. 2015;23(4):335-59.

40. Shah TM, Weinborn M, Verdile G, Sohrabi HR, Martins RN. Enhancing Cognitive Functioning in Healthly Older Adults: a Systematic Review of the Clinical Significance of Commercially Available 
Computerized Cognitive Training in Preventing Cognitive Decline. Neuropsychology Review. 2017;27(1):62-80.

41. Chong TW, Doyle CJ, Cyarto EV, Cox KL, Ellis KA, Ames D, et al. Physical activity program preferences and perspectives of older adults with and without cognitive impairment. Asia-Pacific Psychiatry. 2014;6(2):179-90.

42. Cox KL, Flicker L, Almeida OP, Xiao J, Greenop KR, Hendriks J, et al. The FABS trial: a randomised control trial of the effects of a 6-month physical activity intervention on adherence and long-term physical activity and self-efficacy in older adults with memory complaints. Preventive medicine. 2013;57(6):824-30.

43. Wolff JK, Warner LM, Ziegelmann JP, Wurm S, Kliegel M. Translating good intentions into physical activity: Older adults with low prospective memory ability profit from planning. Journal of behavioral medicine. 2016;39(3):472-82.

44. Bradbury K, Morton K, Band R, May C, McManus R, Little P, et al. Understanding how primary care practitioners perceive an online intervention for the management of hypertension. BMC medical informatics and decision making. 2017;17(1):5.

45. Price AE, Corwin SJ, Friedman DB, Laditka SB, Colabianchi N, Montgomery KM. Older Adults' Perceptions of Physical Activity and Cognitive Health: Implications for Health Communication. Health Education \& Behavior. 2011;38(1):15-24.

46. Devereux-Fitzgerald A, Powell R, Dewhurst A, French DP. The acceptability of physical activity interventions to older adults: A systematic review and meta-synthesis. Social Science \& Medicine. 2016;158:14-23.

47. Lara J, O’Brien N, Godfrey A, Heaven B, Evans EH, Lloyd S, et al. Pilot Randomised Controlled Trial of a Web-Based Intervention to Promote Healthy Eating, Physical Activity and Meaningful Social Connections Compared with Usual Care Control in People of Retirement Age Recruited from Workplaces. PLOS ONE. 2016;11(7):e0159703.

48. Michie S, Abraham C. Advancing the science of behaviour change: a plea for scientific reporting. Addiction. 2008;103(9):1409-10.

49. Gauthier S, Reisberg B, Zaudig M, Petersen RC, Ritchie K, Broich K, et al. Mild cognitive impairment. The Lancet. 2006;367(9518):1262-70.

50. Peels DA, van Stralen MM, Bolman C, Golsteijn RHJ, de Vries H, Mudde AN, et al. The differentiated effectiveness of a printed versus a Web-based tailored physical activity intervention among adults aged over 50. Health Education Research. 2014;29(5):870-82.

51. Lampit A, Hallock H, Valenzuela M. Computerized Cognitive Training in Cognitively Healthy Older Adults: A Systematic Review and Meta-Analysis of Effect Modifiers. PLOS Medicine. 2014;11(11):e1001756.

52. Notthoff N, Klomp P, Doerwald F, Scheibe S. Positive messages enhance older adults' motivation and recognition memory for physical activity programmes. European journal of ageing. 2016;13(3):251-7. 
53. Langa KM, Levine DA. The diagnosis and management of mild cognitive impairment: A clinical review. JAMA. 2014;312(23):2551-61.

54. LaMonica HM, English A, Hickie IB, Ip J, Ireland C, West S, et al. Examining Internet and eHealth practices and preferences: survey study of Australian older adults with subjective memory complaints, mild cognitive impairment, or dementia. Journal of medical Internet research. 2017;19(10):e358.

55. Aalbers T, Baars M, Rikkert MO. Characteristics of effective Internet-mediated interventions to change lifestyle in people aged 50 and older: a systematic review. Ageing research reviews. 2011;10(4):48797.

56. Clemson L, Fiatarone Singh MA, Bundy A, Cumming RG, Manollaras K, O'Loughlin P, et al. Integration of balance and strength training into daily life activity to reduce rate of falls in older people (the LiFE study): randomised parallel trial. BMJ : British Medical Journal. 2012;345:e4547.

57. Irvine AB, Gelatt VA, Seeley JR, Macfarlane P, Gau JM. Web-based intervention to promote physical activity by sedentary older adults: randomized controlled trial. Journal of Medical Internet Research. 2013;15(2):e19.

58. Peels DA, van Stralen MM, Bolman C, Golsteijn RH, de Vries H, Mudde AN, et al. Development of webbased computer-tailored advice to promote physical activity among people older than 50 years. $\mathrm{J}$ Med Internet Res. 2012;14(2):e39.

59. Müller AM, Khoo S. Non-face-to-face physical activity interventions in older adults: a systematic review. International Journal of Behavioral Nutrition and Physical Activity. 2014;11(1):35.

\section{Additional Files}

Additional Table 1 (.pdf) - Intervention actions employed in each phase of the Active Brains development process

Additional Table 2 (.pdf) - Search strategies employed in reviewing conducted during development phase Additional Table 3 (.pdf) - Excerpts from Table of Changes

Additional Table 4 (.pdf) - Behavioural analysis of Active Brains using the Behaviour Change Wheel (BCW) and Theoretical Domains Framework (TDF)

Additional Figure 1 (.pdf) - Full Active Brains intervention logic model

\section{Figures}




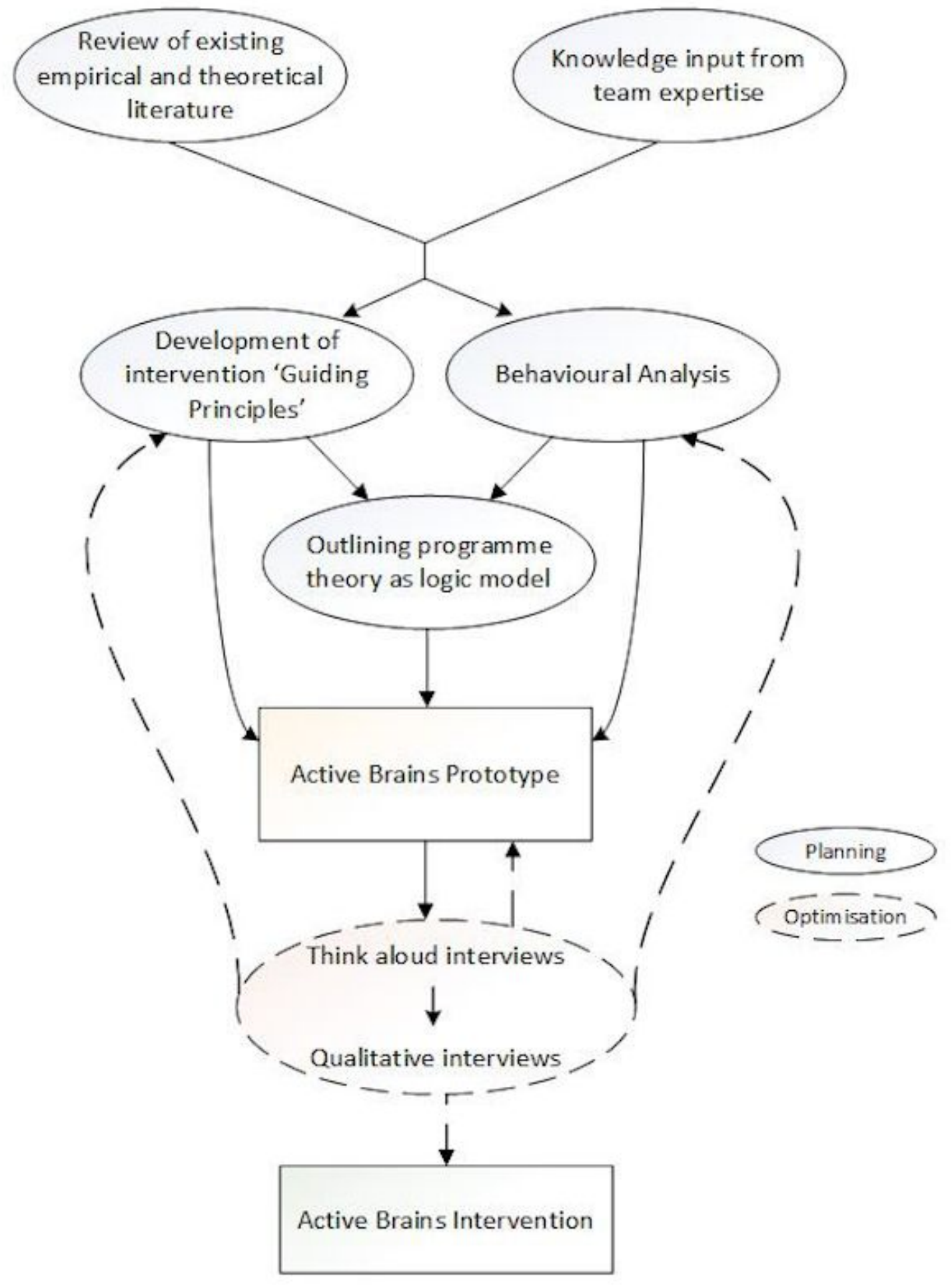

\section{Figure 1}

Planning and optimisation processes involved in the development of Active Brains 


To reduce/prevent
cognitive decline in adults
aged $60-85$ by increasing:
1) Frequency, intensity
and duration of physical
activity behaviour

2) Participation in regular
brain training activity
3) Intake of healthy food/
replacement/reduction of
less healthy options.

Intervention content:
1) ACTIVE LIVE:
Getting Active:
promoting increasing in
physical activity
frequency, intensity
and/or duration
Strength and Balance:
promoting uptake of
strength and balance
training exercises
Breaks from Sitting:
promoting reduction of
sedentary behaviours
2) BRAIN TRAINING:
promoting regular
participation in brain
training activities and
provision of 12 brain
training games
3) EAT FoR HEALTH:
promoting uptake of
healthy eating plan with
benefits for cognitive
and general health

Key intervention features:
Focus on additional benefits for
immediate general health,
enjoyment and mood
Provision of information/
instruction about activities
Tailored goal setting and review
Addressing common concerns
Remote behavioural coaching
(support group only)
Narrative 'success stories'
Motivational and reminder
emails

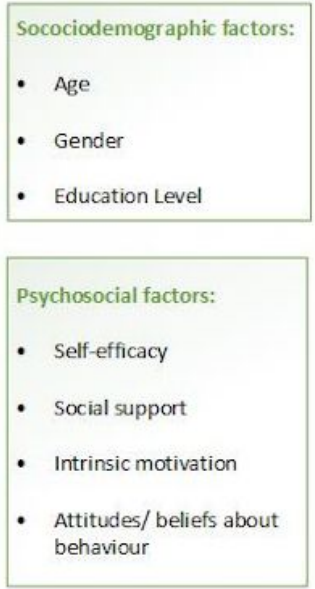

\section{Cont extual factors:}

- Perceived health status

- Perceived usability of Active Brains

- Perceptions of lived environment

- Engagement with Active Brains intervention

Physical activity beha viours:
Increased frequency,
duration and/or intensity of
physical activity behaviour
Regular and frequent
performance of strength and
balance training exercises
Reduced sedentary time
Brain Training behaviours:
Frequent and regular
participation in brain training
games
Increased engagement with
daily life activities of benefit
to cognitive health

Primary Outcomes:

Maintenance, or reduction in decline, in verbal reasoning performance

Secondary Outcomes:

Increased/ maintenance of functioning in activities of daily living

Maintenance or reduction in decline in additional cognitive domains:

- spatial working memory

- attention

- verbalshort-term memory

Increased enablement

Reduced experience of depression

Long-term reduced incidence of dementia (at 5 year follow up)

Improved mortality rates

Improved health-related quality of life

Figure 2

Active Brains Summary Logic Model

\section{Supplementary Files}

This is a list of supplementary files associated with this preprint. Click to download.

- TIDieRChecklistforPandFSsubmission.docx

- AdditionalTable4.pdf

- AdditionalTable2.pdf

- AdditionalFigure1.pdf

- AdditionalTable3.pdf

- AdditionalTable1.pdf 